\title{
Análise de Viabilidade Técnica da Aplicação de Energia Termossolar em Processos de Pasteurização
}

\author{
Technical Feasibility Analysis of Thermal Solar Energy Application at Pasteurization \\ Processes
}

Isaias Moura de Moraes Silva 1,2 (id) https://orcid.org/0000-0001-5530-3023

Luis Arturo Gómez-Malagón 1 (D) https://orcid.org/ 0000-0002-5199-9390

\footnotetext{
${ }^{1}$ Escola Politécnica de Pernambuco, Universidade de Pernambuco, Recife, Brasil,

${ }^{2}$ Especialização em Energia Solar e Eólica, Escola Politécnica de Pernambuco, Pernambuco, Brasil,

E-mail do autor principal: Isaias Moura isaias.moura@hotmail.com
}

\section{RESUMO}

O aumento da demanda mundial por energia tem propiciado o desenvolvimento de tecnologias voltadas para o uso de fontes renováveis de energia, como por exemplo, a energia solar térmica. 0 uso do sol para aquecer a água é particularmente interessante para alguns ramos da indústria, onde se utiliza água numa temperatura entre $60^{\circ} \mathrm{C}$ e $260^{\circ} \mathrm{C}$, como a indústria de alimentos. O Estado de Pernambuco dispõe de um Arranjo Produtivo Local (APL) de laticínios, localizada no agreste meridional e central, onde a energia empregada para aquecimento de água é obtida principalmente a partir da combustão da lenha, a qual gera impactos negativos para o meio ambiente. Com o intuito de identificar o potencial do uso da tecnologia termossolar no processo de pasteurização de leite, foi empregado o software TRNSYS para simular a resposta térmica de uma pequena planta solar térmica que poderia ser usada nessas indústrias. Foi verificado que, o sistema de coletores solares de tubos a vácuo acoplado a um tanque de armazenamento e um sistema de aquecimento convencional, atende as demandas de calor no processo de pasteurização. Desta forma, o uso da energia termossolar nas indústrias de pasteurização pode gerar benefícios econômicos, impactos positivos ao meio ambiente e diminuição dos riscos de operação e manuseio em comparação às caldeiras a lenha.

PALAVRAS-CHAVE: Energia Solar Térmica; Aquecimento solar de água; Pasteurização.

\section{ABSTRACt}

The increase in world demand for energy has led to the development of technologies aimed at the use of renewable energy sources, such as solar thermal energy. The use of the sun to heat the water is particularly interesting for some branches of the industry, where water is used at a temperature between $60^{\circ} \mathrm{C}$ and $260^{\circ} \mathrm{C}$, such as the food industry. The state of Pernambuco (Brazil) has a network of micro-industries (Local Productive Arrangement) for dairy products, located in the southern and central semi-arid region, where the energy used for heating water is obtained mainly from the combustion of firewood (wood-fired boiler), which generates negative impacts on the environment. In order to identify the potential of the solar thermal technology in the process of pasteurizing milk, simulations of the thermal response of the system were made, with TRNSYS software, of a small solar thermal plant that could be used in these industries. It has been found that the vacuum tube solar collector system coupled to a storage tank and a conventional heating system meets the heat demands in the pasteurization process. In this way, the use of solar thermal energy in the pasteurization industries can generate economic benefits, positive impacts to the environment and decrease the risks of operation and handling compared to wood burning boilers.

KEY-WORDS: Thermal Solar Energy; Solar water heating; Pasteurization. 


\section{INTRODUÇÃO}

No Brasil, a energia solar térmica ainda é usada majoritariamente para fins residenciais, aquecendo a água do banho, principalmente nas regiões sul e sudeste.

A indústria ainda tem muito espaço para avançar no uso de energia solar térmica, visto que quase todos os processos industriais exigem calor. Na Europa, $15 \%$ da energia consumida na indústria é para aquecimento, e $13 \%$ das aplicações industriais térmicas exigem temperaturas de até $100^{\circ} \mathrm{C}$ [1]. A indústria de alimentos, por exemplo, faz uso de água aquecida a temperaturas abaixo de $120^{\circ} \mathrm{C}$.

A pasteurização do leite é um desses processos. Ela consiste em submeter o leite a um choque térmico, aquecendo-o a uma temperatura de $75^{\circ} \mathrm{C}$ e resfriando-o logo em seguida (pasteurização rápida). A cadeia produtiva do leite apresenta grande relevância socioeconômica para a Região Nordeste, sendo uma das atividades mais presentes no semiárido. Porém, o baixo nível tecnológico aplicado na exploração leiteira e a falta de gestão mais profissionalizada nas propriedades conferem ao segmento produtivo indicadores técnicos aquém das suas reais potencialidades [2]. Sendo assim, a inserção da energia solar térmica nesse processo representa uma forma de otimizar o consumo energético dessa indústria.

A produção de leite em Pernambuco, no primeiro trimestre de 2018 , foi superior a $55 \mathrm{mil}$ litros, ficando em terceira posição atrás dos Estados do Ceara e Bahia. [3].

Além disso, o Nordeste é geograficamente privilegiado em se tratando de irradiância solar. Pernambuco tem uma insolação diária média anual de 7 horas e radiação global média de $5,9 \mathrm{kWh} / \mathrm{m}^{2}$ [4]. Adicionalmente, e devido a sua proximidade à linha do equador, faz com que não haja grande variação na irradiância solar recebida ao longo do ano.

Atualmente, o Arranjo Produtivo Local (APL) do leite de Pernambuco utiliza aquecedores elétricos, caldeiras a gás e caldeiras a lenha para aquecer a água usada na pasteurização do leite.

Em forma similar a outros empreendimentos, a instalação de sistemas térmicos solares no APL traria benefícios econômicos no médio prazo, com a redução do consumo de eletricidade, gás e lenha, e benefícios ambientais no longo prazo, com a diminuição de gases de combustão gerados na queima da lenha e gás combustível [5].

83
Desta forma, o presente trabalho visa realizar um estudo de viabilidade técnica do uso da energia solar térmica no processo de pasteurização de leite, através do levantamento das demandas de calor de processo de uma planta de pequeno porte, simulação do comportamento térmico da planta usando o software TRNSYS, determinação da fração solar e analise dos resultados.

\section{FUNDAMENTAÇÃO TEÓRICA}

\subsection{Pasteurização}

A pasteurização é um tratamento térmico, no qual o alimento é submetido a um aquecimento por tempo determinado seguido de um rápido resfriamento [6]. A pasteurização tem como objetivo principal a destruição de microorganismos patogênicos e deterioradores e/ou enzimas indesejáveis presentes no alimento. 0 objetivo secundário é aumentar a vida de prateleira, com a mínima redução dos valores nutricionais e sensoriais do alimento. Dependendo do tipo de pasteurização utilizado e as condições de armazenamento e embalagem, os produtos pasteurizados podem conter, ainda, organismos vivos capazes de crescer, o que limita sua vida de prateleira. Assim, a pasteurização é, muitas vezes, combinada com outros métodos de conservação e muitos produtos pasteurizados são estocados sob refrigeração [7].

No Brasil é obrigatório que todo o leite, assim como todos os derivados de lacticínios, seja fabricado a partir do leite pasteurizado [8].

Para a pasteurização de alimentos líquidos não muito viscosos, normalmente são utilizados trocadores de calor de placas, PHE (Plate Heat Exchanger), como mostrado na figura 1, onde são mostrados as três seções de troca térmica e o tubo de retenção.

Este tipo de trocador é o que melhor atende às exigências de higiene e limpeza das indústrias alimentícias e farmacêuticas, pois eles podem ser desmontados, limpos e inspecionados e apresentam maior facilidade no controle de temperaturas, essencial para os processos de pasteurização e esterilização [9]. 


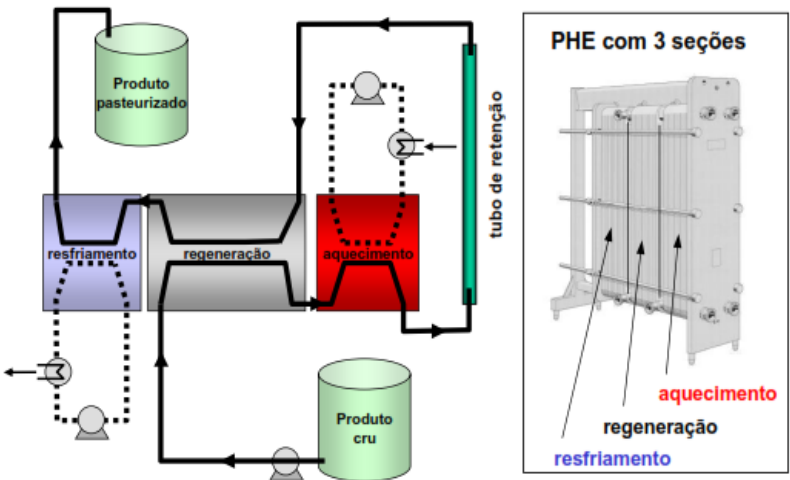

Figura 1: Pasteurizador de placas planas.

Fonte: [10]

Nos processos de pasteurização, o controle da temperatura nas diferentes etapas do processo é muito importante, especialmente na saída do tubo de retenção, que é o encarregado de manter o produto no tempo e na temperatura definidos para o processo. Durante a passagem do produto através do tubo de retenção ocorre a destruição de micro-organismos e a inativação de enzimas, portanto, se a temperatura de saída do tubo de retenção for menor do que a estabelecida, o produto terá que ser novamente processado para garantir a segurança microbiológica. Pelo contrário, se a temperatura de saída for maior, o produto estaria sendo sobre processado. Como consequência, em ambos os casos, com importantes perdas de qualidade do alimento, assim como incremento nos custos de produção.

Assim como em outros alimentos, o microrganismo mais termo-resistente no leite é o bacilo da Tuberculose, sendo assim, ele é considerado como referência no tratamento térmico do leite, já que qualquer tratamento térmico neste alimento que destrua este microrganismo terá também destruído os outros micro-organismos, assegurando assim uma redução importante na flora microbiana.

$\mathrm{Na}$ literatura são encontrados três tipos de pasteurização: lenta, rápida e muito rápida.

$\mathrm{Na}$ pasteurização lenta são utilizadas temperaturas menores durante um intervalo maior de tempo. Este tipo de pasteurização é a mais adequada para pequenas quantidades de leite, por exemplo, o leite de cabra, onde a temperatura utilizada é de $65^{\circ} \mathrm{C}$ durante 30 minutos.

A pasteurização rápida também chamada como pasteurização HTST (High Temperature Short Time) é aquela onde são utilizadas altas temperaturas durante curtos intervalos de tempo, aproximadamente $75^{\circ} \mathrm{C}$ durante 15 a 20 segundos sendo mais utilizada para leite tipo A, B e C. A eficiência desta pasteurização é de aproximadamente $95 \%$, portanto, o produto precisa de refrigeração. O tempo de prateleira desta pasteurização é aproximadamente 5 dias para o leite. A figura 2 apresenta o perfil temporal da temperatura no processo HTST.

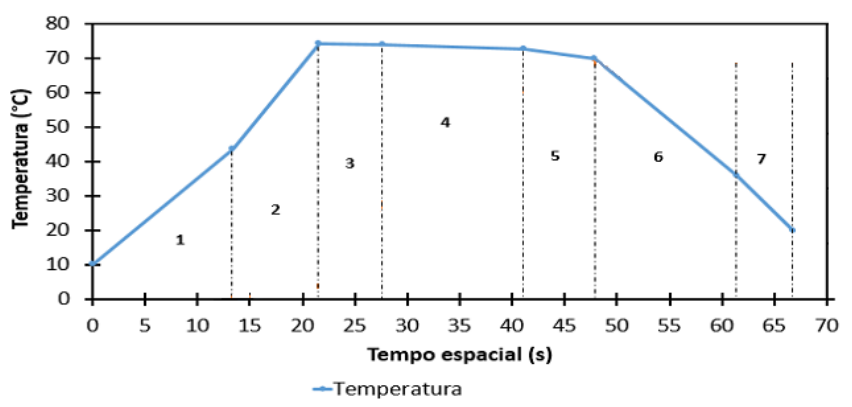

Figura 2: Perfil de temperaturas do processo HTST. Fonte: [11]

Neste processo, o leite cru integral e bombeado ao trocador de calor de placas a $10^{\circ} \mathrm{C}$, onde será pré-aquecido na seção de regeneração até a temperatura de $43^{\circ} \mathrm{C}$. Neste ponto será dirigido ao conjunto de padronização / desnate para acerto do teor de gordura. Após a seção de regeneração o produto será aquecido até a temperatura de $75^{\circ} \mathrm{C}$ mediante a circulação em contracorrente de água quente. Após a seção de aquecimento, o produto será enviado ao tubo de retenção, onde permanecerá por 16 segundos. Atingida a temperatura de pasteurização desejada, o leite será resfriado por efeito regenerativo até a temperatura aproximada de $39^{\circ} \mathrm{C}$, sendo posteriormente resfriado a $17^{\circ} \mathrm{C}$ mediante a circulação em contracorrente de água gelada.

A pasteurização muito rápida, denominada UHT (Ultra High Temperature) também é conhecida como "longa vida", devido ao tempo de prateleira de aproximadamente 4 meses em estocagem a temperatura ambiente. As temperaturas utilizadas nesta pasteurização vão de $130^{\circ} \mathrm{C}$ a $150^{\circ} \mathrm{C}$, durante 3 a 5 segundos, conseguindo uma eficiência de aproximadamente $99,99 \%$, onde todas as formas vegetativas das bactérias são eliminadas e o produto torna-se "comercialmente estéril", sendo possível a presença de algumas formas esporuladas que podem eventualmente sobreviver, mas que não conseguirão se desenvolver nas condições de estocagem [7]. 
Neste trabaiho será estudado um sistema termossolar que possa atender as demandas de calor do processo HTST, o qual é tipicamente empregado no APL de laticínios.

\subsection{Coletores de tubos a vácuo}

Coletores solares de tubos a vácuo se apresentam como uma tecnologia que pode ser empregada para atender as demandas típicas de processos industriais que operam entre $50{ }^{\circ} \mathrm{C}$ e $200{ }^{\circ} \mathrm{C}$. Sistemas baseados na tecnologia de tubos a vácuo aproveitam melhor a radiação difusa, portanto funcionam razoavelmente bem mesmo em dias nublados [12].

A estrutura deste tipo de coletor consiste em dois tubos concêntricos de vidro borossilicato como mostrado na figura 3. O tubo interno é revestido com uma camada de material absorvedor de calor, e entre estes tubos há vácuo, responsável pela redução de perdas por condução e convecção.

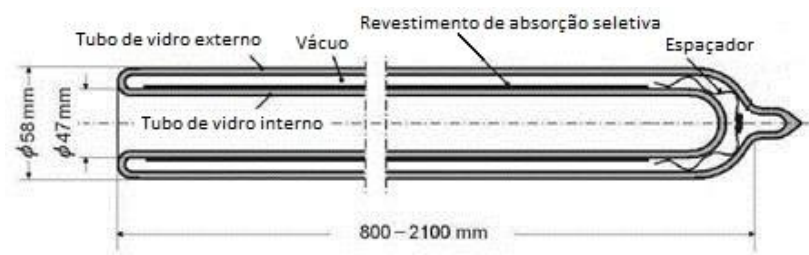

Figura 3: Coletor de tubos a vácuo.

Fonte: Adaptado de [13].

O calor absorvido pode ser extraído usando um tubo de calor ou inserindo o liquido de trabalho dentro do tubo.

No primeiro caso, o tipo com o tubo de calor é conhecido pelo seu termo em inglês, heat pipe. Este tubo, geralmente de cobre, tem um pequeno diâmetro (menor que $10 \mathrm{~cm}$ ), é preenchido por um líquido condutor de calor, que foi inserido a baixa pressão, para diminuir seu ponto de ebulição. Este tubo metálico se estende até fora do tubo de vidro, no que se chama de câmara de irradiação, como pode ser visto na figura 4 . É esta câmara que é inserida no coletor de água a ser aquecida. $\mathrm{O}$ líquido no interior do tubo de calor recebe a irradiação solar, aquece e é elevado à câmara de irradiaçao, por diferença de densidade, onde transfere calor para a água que envolve a câmara. Após a transferência de calor, o líquido dentro da câmara retorna para a base do tubo de calor e reinicia o processo.

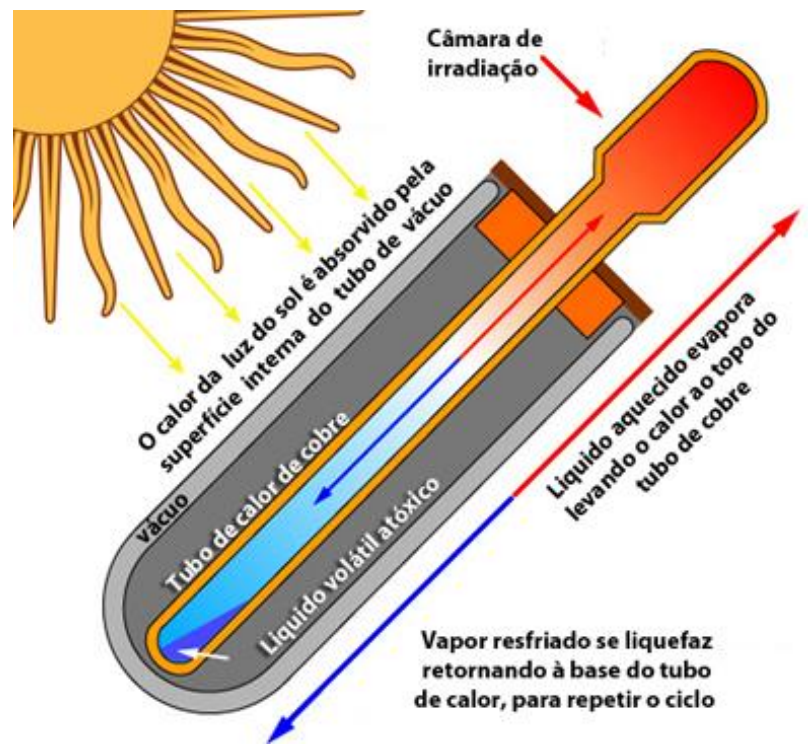

Figura 4: Coletor de tubos a vácuo tipo Heat Pipe. Fonte: [14].

Nos modelos sem o heat pipe, também conhecido como water-in-glass, o processo é semelhante, só que o líquido responsável pela troca de calor, flui no interior do próprio tubo de vidro, como indicado na figura 5 .

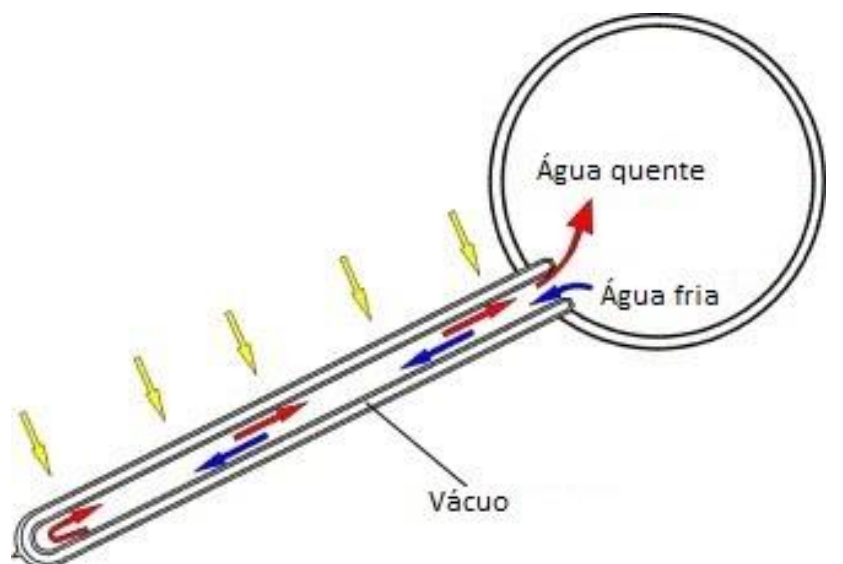

Figura 5: Coletor de tubos a vácuo tipo Water-in-glass. Fonte: Adaptada de [15]. 


\section{Métodos}

O dimensionamento adequado dos componentes de um sistema termossolar é um problema complexo, que inclui componentes previsíveis (coletor e outras características de desempenho) e imprevisíveis (dados climáticos).

A etapa inicial na modelagem de um sistema é a derivação de uma estrutura a ser usada para representar o sistema. Ao desenvolver uma estrutura para representar um sistema, os limites do sistema consistentes com o problema que está sendo analisado devem ser estabelecidos inicialmente. Isso é feito especificando quais itens, processos e efeitos são internos ao sistema e quais itens, processos e efeitos são externos. [1]

O desempenho térmico do sistema foi determinado usando o software TRNSYS, o qual é um programa de simulação de sistemas em regímen transitória [16]. Neste programa, foi determinado o perfil de temperatura e fluxo de calor nos componentes do sistema, a partir da simulação horaria das variáveis do processo, considerando as informações de radiação solar, disponíveis na base de dados para o ano solar médio da cidade de Recife.

\subsection{Requisitos do Processo}

Tipicamente, as pasteurizadoras que empregam o processo HTST usam resistências elétricas ou vapor para aquecer o leite. Neste estudo, a planta proposta terá uma fonte convencional de energia e um sistema auxiliar baseado em energia solar.

A energia que deve ser absorvida pelo leite no processo de aquecimento é dada por:

$$
\dot{Q}_{l}=\dot{m}_{l} * C_{p, l}\left(T_{\text {saída,l }}-T_{\text {entrada }, l}\right)
$$

onde $\dot{m}_{l}$ é a vazão em $\mathrm{kg} / \mathrm{s}$ do leite circulando pelo trocador de calor, $C_{p, l}$ é a capacidade calorifica do leite $(3,93 \mathrm{~kJ} / \mathrm{K} / \mathrm{kg})$, e $T_{\text {entrada,l }}$ e $T_{\text {saída,l }}$ são as temperaturas do leite na entrada e saída do trocador de calor, respectivamente. Considerando que a pasteurizadora opera com uma vazão de leite de $1000 \mathrm{l} / \mathrm{h}$, funcionando das $10 \mathrm{~h}$ da manhã às $14 \mathrm{~h}$ da tarde, e que o sistema no estágio de aquecimento deve ser capaz de aumentar a temperatura do leite de $55^{\circ} \mathrm{C}$ para $75^{\circ} \mathrm{C}$, o consumo de energia dado pela equação (1) é de $78600 \mathrm{~kJ} / \mathrm{h}(22 \mathrm{~kW})$.

Esta energia é fornecida pela água que circula pelo trocador de calor, onde será considerado que a eficiência global de transmissão de calor, $\eta$, é de $80 \%$. Desta forma, a energia fornecida pela água é dada por:

$$
\dot{Q}_{\text {água }}=\frac{\dot{Q}_{\text {leite }}}{\eta} .
$$

De forma análoga à equação (1), a vazão de água no trocador de calor foi determinada considerando que o sistema de aquecimento de água fornece água a $85^{\circ} \mathrm{C}$ e que a temperatura da água na saída do trocador é de $55^{\circ} \mathrm{C}$.

\subsection{Modelo do Sistema}

A figura 6 mostra o esquema da planta que foi estudada. Neste diagrama podem ser identificados o circuito primário onde está o coletor solar, o circuito secundário ou de carga, onde está a caldeira ou fonte convencional de energia, e finalmente o trocador de calor da pasteurizadora.

No circuito primário foi empregado o coletor solar de tubos a vácuo do tipo water-in-glass, o qual é facilmente comercializado no Brasil com o selo do INMETRO. O modelo do coletor recebe informações meteorológicas relativas à cidade de Recife para simular sua resposta térmica. A bomba de circulação de água tem um controle de temperatura que permite seu acionamento somente quando a temperatura de saída do coletor está acima da temperatura do tanque em $2{ }^{\circ} \mathrm{C}$.

O tanque possui duas entradas e duas saídas, sendo um par para o circuito do coletor solar e outro para o circuito de carga. Para estabelecer a estratificação de temperatura no tanque, a entrada de água quente proveniente do coletor, e a saída de água quente para o circuito da carga, foram posicionadas na parte alta do tanque, enquanto as entrada e saída de água fria ficaram embaixo.

No circuito secundário, a água quente proveniente do tanque, entra no símbolo da caldeira, a qual representa a fonte convencional de calor. A temperatura na sua saída é monitorada, para fornecer apenas a quantidade de calor necessária para que a temperatura na sua saída permaneça constante. A água na temperatura desejada segue para a etapa de aquecimento da pasteurizadora. 


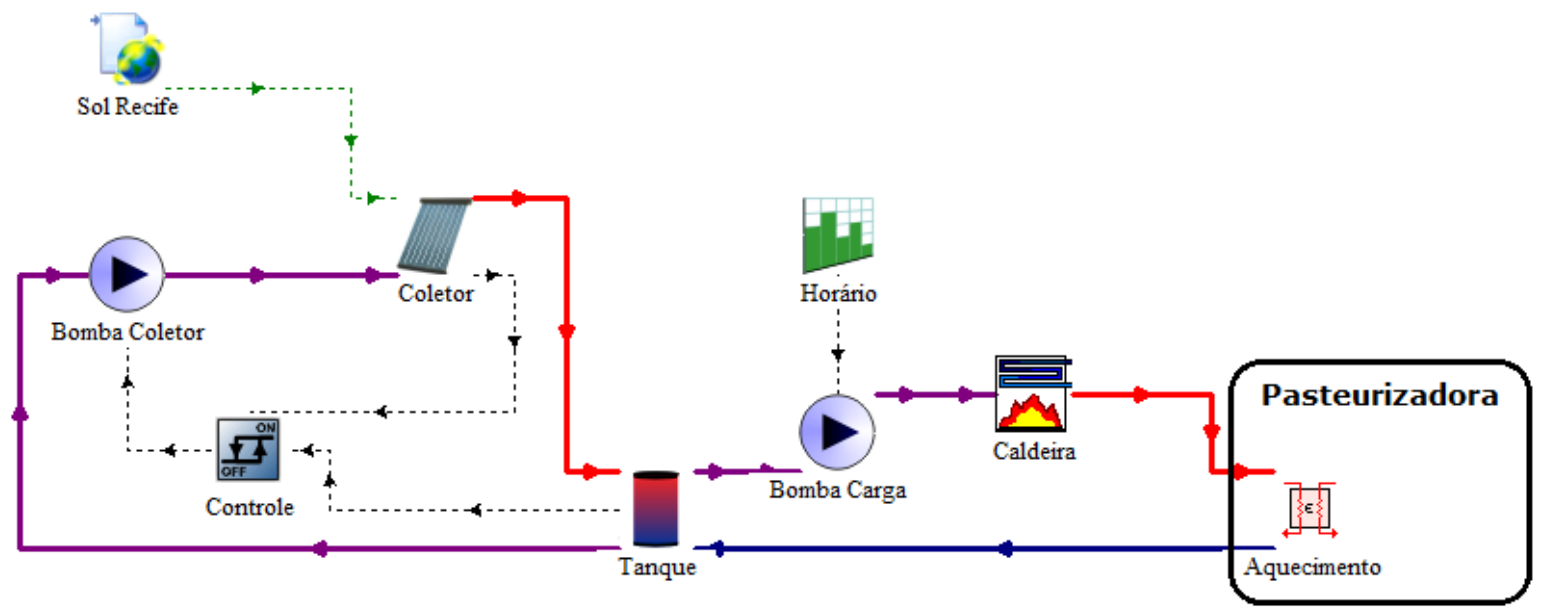

Figura 6: Modelo da planta solar usado no TRNSYS.

Fonte: Elaborado pelo autor.

Por outro lado, a partir das simulações foi possível determinar a fração solar, $f$, definida como a relação entre a energia entregue pelo sistema de aquecimento solar ( $Q_{\text {solar }}$ ) e a energia consumida pelo sistema $\left(Q_{\text {solar }}+Q_{\text {caldeira }}\right)$, assim:

$$
f=\frac{Q_{\text {solar }}}{Q_{\text {solar }}+Q_{\text {caldeira }}}
$$

A resposta térmica da planta depende principalmente da área do coletor e o volume do tanque. Desta forma, a fração solar foi determinada considerando que a área total do coletor varia em múltiplos da área de um coletor unitário. Da mesma forma, os valores do volume do tanque empregado nas simulações correspondem aos valores comerciais.

Os valores dos parâmetros empregados para o coletor solar, tanque e fonte convencional são mostrados no quadro 1.

\section{Quadro 1}

\section{COLETOR SOLAR}

Tipo: Tubos a vácuo water-in-glass

Área coletor unitário com 25 tubos $\left(\mathrm{m}^{2}\right) \quad 4,65$

\begin{tabular}{l|r}
\hline$F_{R}(\tau \alpha)_{n}$ & 0,771 \\
\hline$F_{R} U L /\left(W / m^{2}\right.$ &
\end{tabular}

\begin{tabular}{|r|r|}
\hline$F_{R} U_{L}\left(W / m^{2} K\right)$ & 1,946
\end{tabular}

Inclinação na direção N-S (graus) $\quad 20$

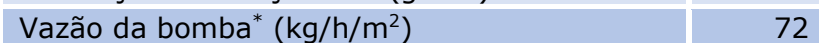

Fonte convencional (Caldeira)

Potência máxima (kW)

Reservatório Térmico

Volume (I)

\section{RESULTADOS}

\subsection{Volume do tanque}

Para analisar o efeito do volume do tanque no desempenho do sistema, foi determinada a resposta temporal da temperatura do tanque considerando volumes de $300 \mathrm{l}, 1000 \mathrm{I}$ e $3000 \mathrm{I}$ e a área de coletor de $9,3 \mathrm{~m}^{2}$. O resultado desta simulação é apresentado na figura 7. Observe que, quanto menor o tanque, sua temperatura é maior, e sua resposta é mais rápida quando as bombas do circuito primário e secundário são ligadas. No caso do volume do tanque de $300 \mathrm{I}$, sua temperatura chega no valor mínimo antes do processo de pasteurização terminar. Neste caso, a fonte convencional de energia irá suprir a maior parte de energia do processo. Por outro lado, no caso do volume de $3000 \mathrm{I}$, a temperatura é menor e varia muito pouco durante o processo de pasteurização, indicando que a fonte convencional deverá suprir energia de forma constante. Para que o sistema termossolar seja insensível à capacidade do tanque, é recomendado que o volume seja major do que $50 \mathrm{l} / \mathrm{m}^{2}$ coletor [12].

Desta forma, para as simulações do sistema, escolheu-se um tanque de 1000 l por ter um comportamento intermediário.

*Segundo ISO 9806-1:1994 [17]. 


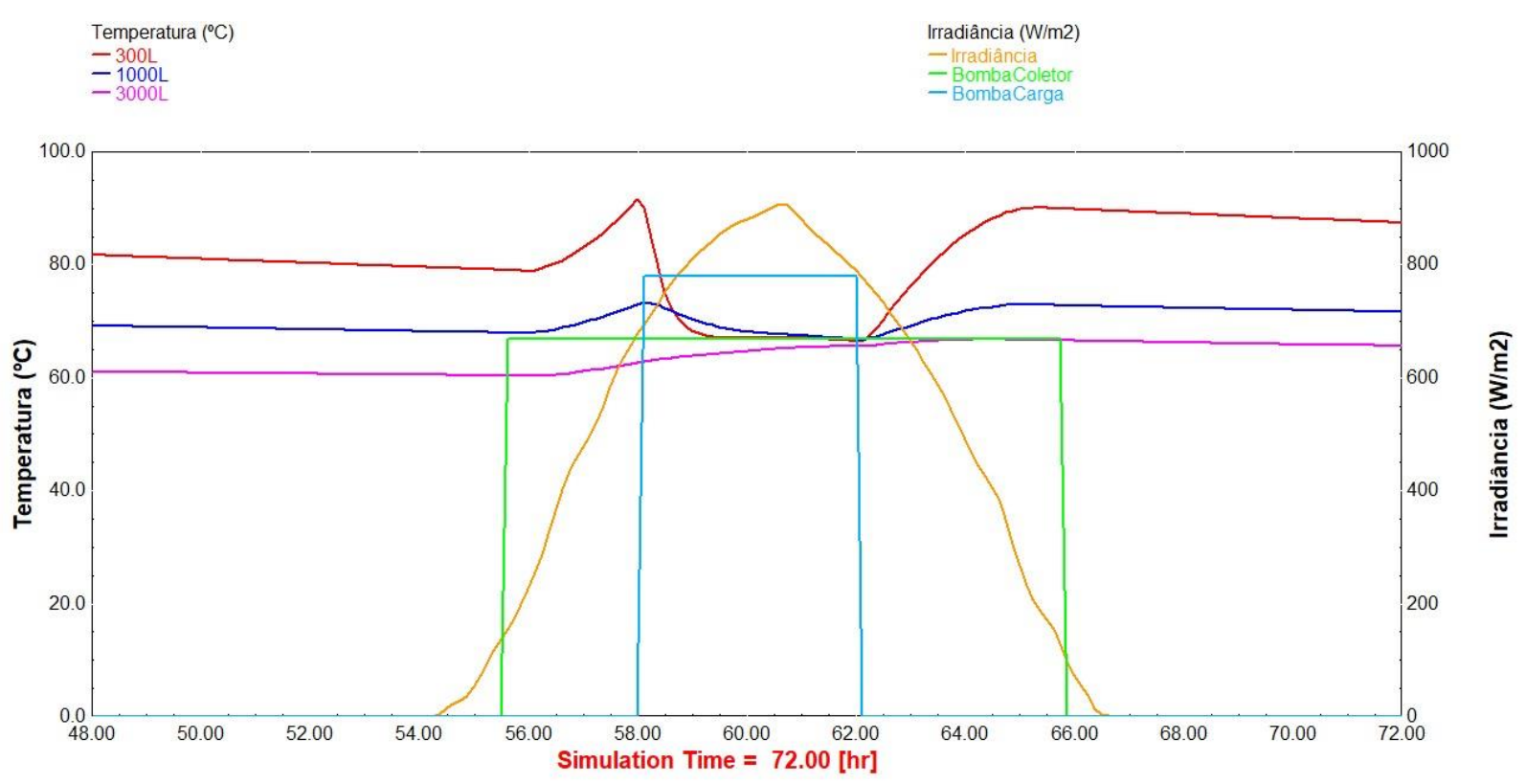

Figura 7: Evolução temperatura na saída do tanque considerando volumes diferentes.

Fonte: Elaborado pelo autor.

\subsection{Circuito primário}

A figura 8 mostra, por exemplo, a resposta térmica do circuito primário, durante o terceiro dia do mês de janeiro, considerando um coletor $(4,65$ $\left.\mathrm{m}^{2}\right)$.

A temperatura na saída do coletor (ColSaida), está sempre acima da temperatura do tanque (TanqueSaída). Após o coletor receber energia solar, indicada pela curva de irradiância, a bomba do coletor é acionada automaticamente por causa da diferença de temperatura entre coletor e tanque estabelecida no sistema de controle. Isso faz a temperatura do tanque subir, acompanhando a temperatura do coletor. A queda de temperatura no tanque acontece quando é acionada a bomba do circuito de carga, ou seja, quando a pasteurizador está funcionando. Esse comportamento se manteve regular ao longo do ano.

\subsection{Circuito Secundário}

Neste circuito será analisada, a partir da figura 9, a temperatura da água na saída do tanque (Tanque saída), a temperatura na saída do sistema convencional (CaldSaida), a temperatura do leite na saída da pasteurizadora (LeiteSaida), assim como a energia consumida pelo processo de pasteurização (Qpast), e a energia entregue pelo sistema termossolar (Qtanque) e o sistema convencional (QCald). Como já foi analisado na seção 4.1, com o volume do tanque de 1000 I, a temperatura do tanque tende a aumentar até que a bomba do circuito secundário é acionada. A partir desse instante, a fonte convencional entrega energia a água até atingir seu valor máximo estabelecido em $85^{\circ} \mathrm{C}$. Desta forma foi verificado que a temperatura de processo de $75{ }^{\circ} \mathrm{C}$ foi atingida.

Durante o funcionamento da pasteurizadora, podemos analisar o fluxo de energia. O consumo total de energia pela pasteurizadora é de aproximadamente $22 \mathrm{~kW}$, em concordância com o previsto pela equação (1), e o tanque entrega energia durante todo o processo, tendo sua maior contribuição em seu início. Por outro lado, a fonte convencional entrega uma quantidade maior de energia, também durante todo o processo, e tende a aumentar até o final do processo.

Nesta configuração pode-se observar que a fração de energia entregue pelo sistema termossolar é de $12,51 \%$ da energia total requerida para operar o sistema. 


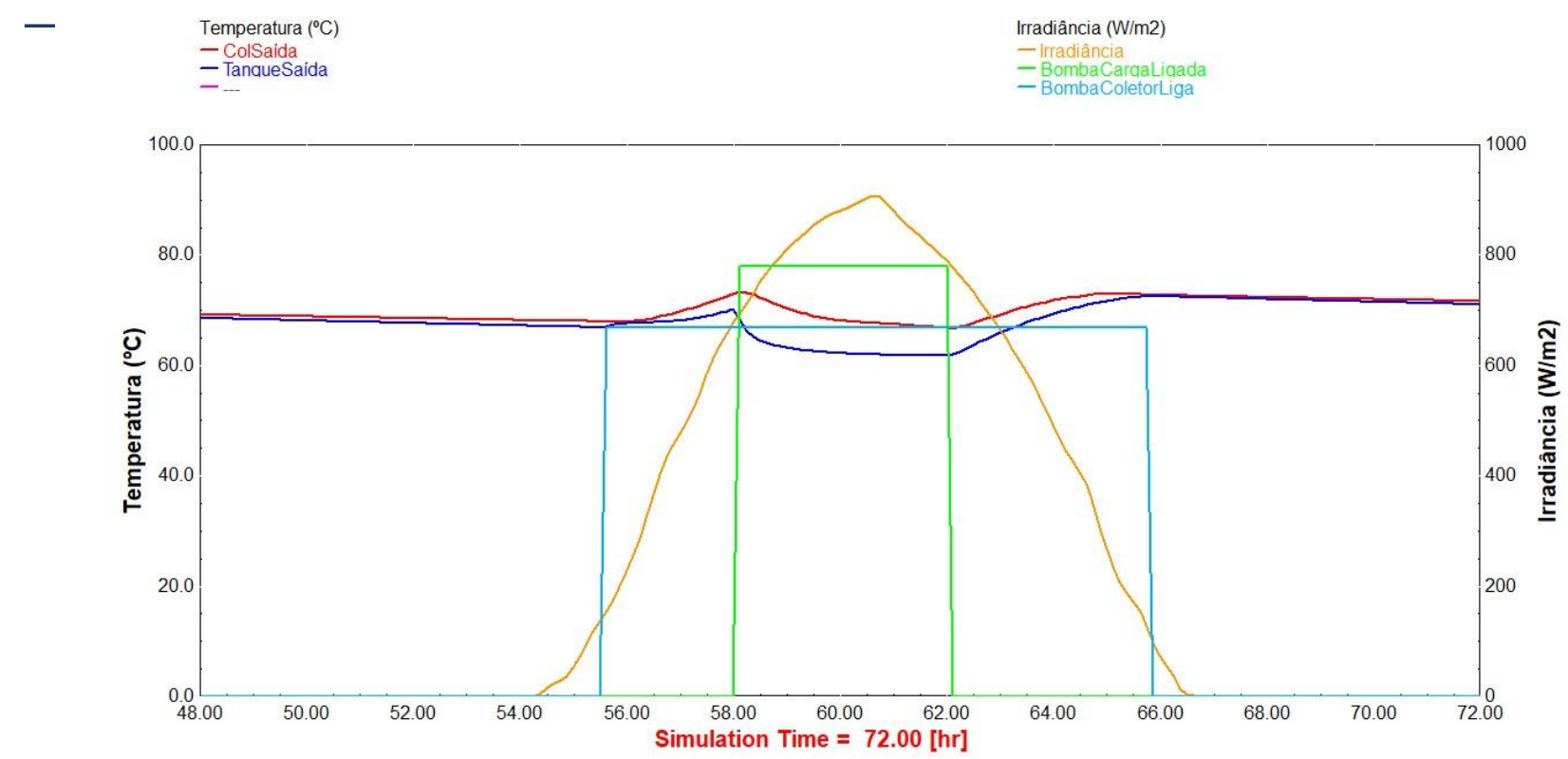

Figura 8: Resposta térmica do circuito do coletor.

Fonte: Elaborado pelo autor.

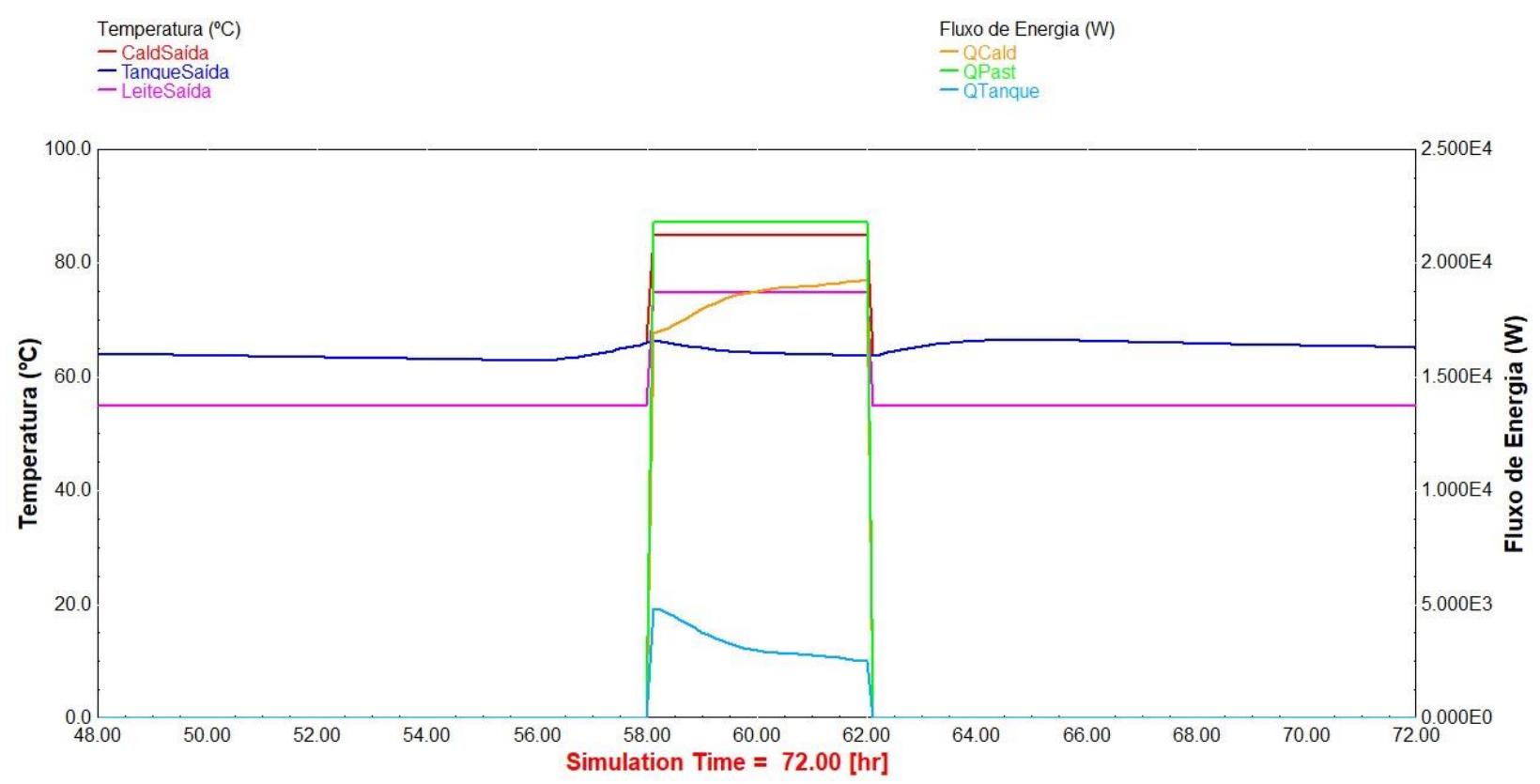

Figura 9 Resposta térmica do circuito de carga.

Fonte: Elaborado pelo autor. 


\subsection{Fração Solar}

O aumento da área do coletor solar vai aumentar a quantidade de energia fornecida pelo sistema termossolar ao processo, e consequentemente vai aumentar a fração solar. Considerando que os coletores estão conectados em paralelo, a figura 10 mostra a resposta térmica do sistema para um arranjo de 5 coletores. Nesta configuração, as temperaturas não são fortemente modificadas em relação às temperaturas obtidas na configuração com um coletor solar. Por outro lado, pode-se observar que no início do processo, a energia entregue pelo tanque é suficiente para atender as demandas de calor de processo. $\mathrm{Na}$ medida que o consumo de energia aumenta, a quantidade de energia entregue pelo tanque diminui e é necessário a participação da fonte convencional para suprir as demandas de calor de processo. Nesta simulação a fração solar média anual foi de $70,39 \%$. Apesar dessa performance, há desvantagens, como o sobreaquecimento no início do funcionamento da pasteurizadora. Mesmo com o sistema convencional desligado, a temperatura passou da desejada, indicando a necessidade de instalação de algum sistema de injeção de água fria no circuito, para controlar a temperatura de entrada na pasteurizadora.
A dependência da fração solar com a área do coletor não é uma relação linear [18]. Para o sistema estudado, esta dependência é mostrada na figura 11.

Nesta figura, podemos observar que o maior ganho é obtido com até 4 coletores, e vai diminuindo com o aumento de coletores chegando quase a ser nulo quando passamos de 9 para 10 coletores. A determinação da área ótima dos coletores para um empreendimento termossolar é um problema econômico, onde deve ser analisado o ganho com o custo da energia substituída, e o custo da implantação do sistema [18].

Para efeitos de comparação, simulações de pasteurizadoras localizadas em Girona-Espanha (Latitude $42,37^{\circ} \mathrm{N}$ ) e Sidi-Bouzid-Tunisia (Latitude $\left.35,04^{\circ} \mathrm{N}\right)$, com sistemas termossolares semelhantes à planta estudada neste trabalho, mostraram uma fração solar média sazonal de aproximadamente $30 \%$ e $58 \%$ com $30 \mathrm{~m}^{2}$ de área dos coletores, respectivamente [5]. No nosso caso, para uma área de $27,9 \mathrm{~m}^{2}$, foi obtida uma fração solar média anual de $79,9 \%$. Para sistemas de grande porte nos Estados Unidos, com área de $4000 \mathrm{~m}^{2}$, frações solares de $29 \%$ e $34 \%$ foram determinadas usando o TRNSYS para as cidades de Madison (Latitude $43,07^{\circ} \mathrm{N}$ ) e Fresno (Latitude $\left.36,74^{\circ} \mathrm{N}\right)$, respectivamente [19].

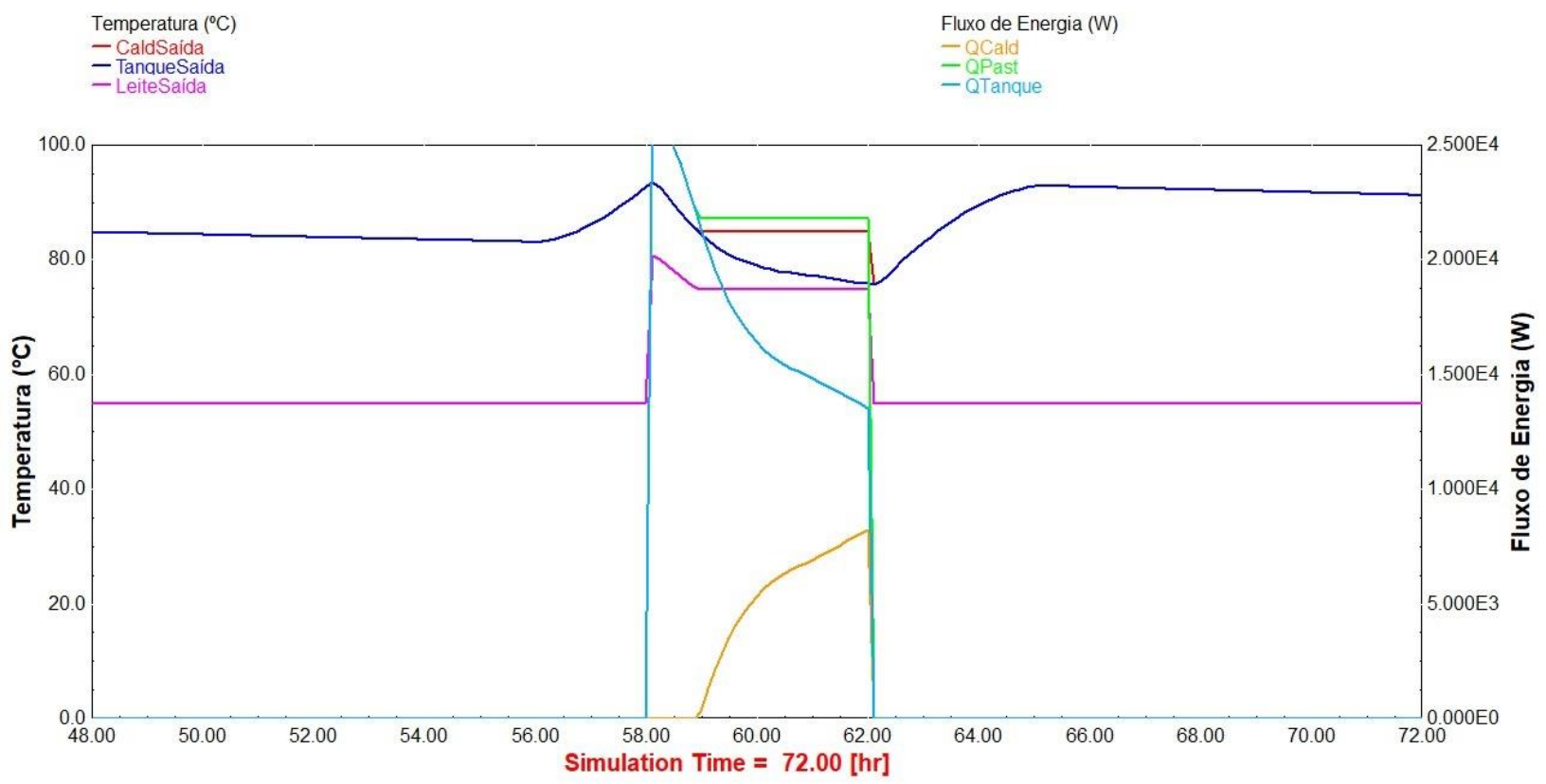

Figura 10: Resposta térmica do circuito de carga, para um arranjo com 5 coletores.

Fonte: Elaborado pelo autor. 


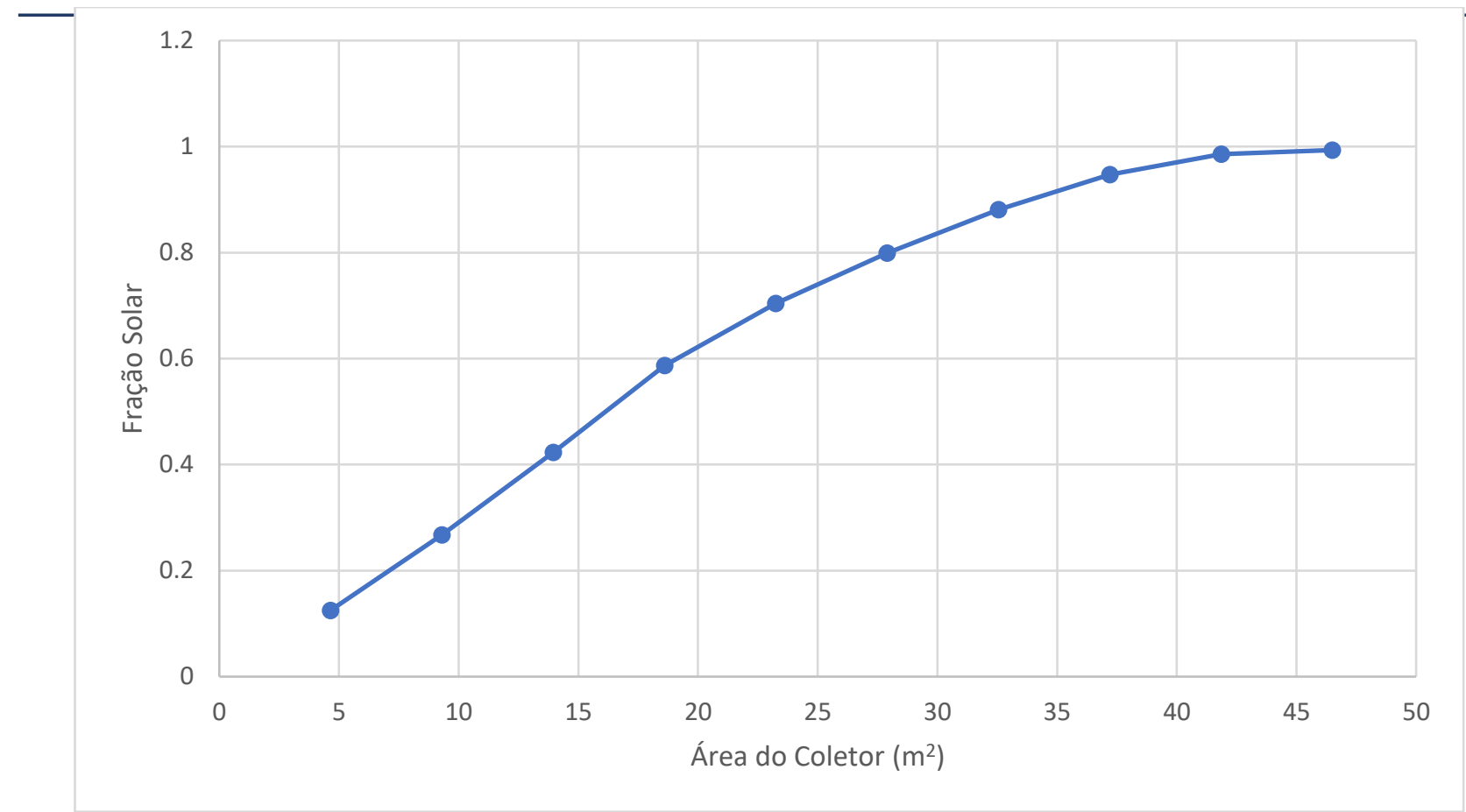

Figura 11: Fração Solar média anual em função da área de coletores.

Fonte: Elaborado pelo autor.

\section{CONCLUSÕES}

O uso da energia termossolar nas indústrias de laticínios para realizar o processo de pasteurização, é uma alternativa viável do ponto de vista técnico, que pode contribuir positivamente, não somente na economia de energia, mas também na redução do impacto ao meio ambiente.

Em vista que, a planta estudada possui um tanque acumulador, a água quente armazenada pode ser usada tanto para a pasteurização rápida como a lenta.

Por outro lado, com o aumento de coletores solares, cresce também o aproveitamento da energia solar em detrimento da convencional, mas seu aumento deliberado pode provocar sobreaquecimento, o que demanda a aplicação de alternativas de controle de temperatura, afetando a eficiência energética do sistema.

Finalmente, a comparação entre as frações solares calculadas para plantas com demandas de calor de processo e áreas do coletor similares, localizadas no Nordeste Brasileiro e em latitudes maiores do que $30^{\circ} \mathrm{N}$, mostra que industrias localizadas no APL de laticínios tem maior potencial para a exploração do recurso solar em seus processos, em comparação com empresas com demandas similares localizadas em altas latitudes.

\section{REFERÊNCIAS}

[1] KALOGIROU, S. The potential of solar industrial process heat applications. Applied Energy, v. 76, n. 4, p. 337-361, 2003.

[2] SANTOS G. O.; DUARTE M. D. O. Diagnóstico do Arranjo Produtivo Local de Laticínios do Agreste Pernambucano. In: CONGRESSO DE INICIAÇÃO CIENTÍFICA, 23., Congresso de Iniciação em Desenvolvimento Tecnológico e Inovação da UFPE, 7., Encontro de Iniciação Científica do Ensino Médio da UFPE, 3. 6-7 abril 2016, Recife. Anais... Recife: UFPE, 2016. Disponível em:

https://www.ufpe.br/documents/616030/926759/ Diagnostico_do_arranjo_prod.pdf/969ee132c4e5-4203-8cd3-e27bc9fc7410

\section{[3] INSTITUTO BRASILEIRO DE GEOGRAFIA E} ESTATÍSTICA. Pesquisa Trimestral do Leite. Disponível em https://www.ibge.gov.br/estatisticasnovoportal/economicas/agricultura-epecuaria/9209-pesquisa-trimestral-doleite. $\mathrm{html}$ ?edicao $=21443 \& \mathrm{t}=$ destaques Acesso em 27/11/2018. 
[4] TIBA, C. Atlas solarimétrico brasileiro. Recife: Ed. Universitária da UFPE, 2000.

[5] ORTEGÓN, A. C.; FELIPE, X.; PRIETO, J.; CORONAS, A. Energy analysis of a solar system for heating and refrigeration in a dairy industrial application. Revue des Energies

Renouvelables Spécial ICT3-MENA, Bou Ismail, p. 27 - 34, 2015

[6] SANCHO, M. F.; RAO, M. A. Residence time distribution in a holding tube. Journal of Food Engineering, v. 15, p.1-19, 1992.

[7] POTTER, N. N.; HOTCHIKISS, J. H. Food Science. 5. ed. New York: Chapman \& Hall, 1995.

[8] BRASIL. Resolução RDC no 267, de 25 de setembro de 2003. Dispõe sobre o Regulamento Técnico de Boas Práticas de Fabricação para Estabelecimentos Industrializadores de Gelados Comestíveis e a Lista de Verificação das Boas Práticas de Fabricação para Estabelecimentos Industrializadores de Gelados Comestíveis. Brasília, DF: AGÊNCIA NACIONAL DE VIGILÂNCIA Sanitária, 2003. Artigo 4.1.16.

[9] KIM, H. B.; TADINI, C.C.; SINGH, R. K. Heat transfer in a plate exchanger during pasteurization of orange juice. Journal of Food Engineering, v. 42, p. 79-84, 1999.

[10] GUT, ]. A. W.; PINTO, J. M. Conhecendo os Trocadores de Calor a Placas. Disponível em: http://www.hottopos.com/regeq11/gut.htm Acesso em 07 dez. 2018.

[11] CANO, I. A.; GUT, J. A. W. Modelagem e Simulação Dinâmica da Pasteurização Contínua de Leite. In: CONGRESSO BRASILEIRO DE ENGENHARIA QUÍMICA, 21., 2016, Fortaleza.

Anais... Fortaleza: ABEQ, 2016.

\section{[12] KALOGIROU, S. Solar Energy} Engineering: Processes and Systems. [s. I.]: Elsevier, 2009.

[13] ALL-GLASS VACUUM-TUBE COLLECTORS. In: SOLAR ENERGY. c2019. Disponível em: http://energyprofessionalsymposium.com/?p=569 7 Acesso em: 17 mar. 2019.

[14] Coletor de tubos a vácuo. Disponível em: http://www.marla.pt/paineis-vacuo.php. Acesso em: 20 dez. 2018.
[15] MORRISON G. L.; Budijardjo I.; Behnia M. Water-in-glass evacuated tube solar water heaters. Solar Energy, v. 76, p. 135-140, 2004.

[16] Transient System Simulation Tool. Disponível em: http://www.trnsys.com/ Acesso em 14 out. 18.

[17] GENEVA. ISO 9806-1:1994, Test methods for solar collectors - Part 1: Thermal performance of glazed liquid heating collectors including pressure drop. GENEVA: International Organization for Standardization, 1994.

[18] DUFFIE, J. A.; BECKMAN, W. Solar Engineering of Thermal Processes. 3.ed. [s. I.] John Wiley \& Sons, 2006.

[19] SINGH, R. K.; Lund D. B.; Buelow H. F.; Duffie J. A. Compatibility of Solar Energy with Fluid Milk Processing Energy Demands. Transactions of the ASAE, v. 23, p. 07620766, 1980. 